\title{
Stream flow simulation and verification in ungauged zones by coupling hydrological and hydrodynamic models: a case study of the Poyang Lake ungauged zone
}

\author{
Ling Zhang ${ }^{1}$, Jianzhong Lu ${ }^{1}$, Xiaoling Chen ${ }^{1,2}$, Dong Liang ${ }^{1}$, Xiaokang Fu ${ }^{1}$, Sabine Sauvage ${ }^{3}$, and \\ José-Miguel Sanchez Perez $^{3}$ \\ ${ }^{1}$ State Key Laboratory of Information Engineering in Surveying, Mapping and Remote Sensing, Wuhan University, \\ Wuhan 430079, China \\ ${ }^{2}$ Key Laboratory of Poyang Lake Wetland and Watershed Research, Ministry of Education, Jiangxi Normal University, \\ Nanchang 330022, China \\ ${ }^{3}$ ECOLAB, Université de Toulouse, CNRS, INPT, UPS, 31400 Toulouse, France
}

Correspondence to: Jianzhong Lu (lujzhong@whu.edu.cn)

Received: 5 February 2017 - Discussion started: 28 February 2017

Revised: 5 August 2017 - Accepted: 2 October 2017 - Published: 24 November 2017

\begin{abstract}
To solve the problem of estimating and verifying stream flow without direct observation data, we estimated stream flow in ungauged zones by coupling a hydrological model with a hydrodynamic model, using the Poyang Lake basin as a test case. To simulate the stream flow of the ungauged zone, we built a soil and water assessment tool (SWAT) model for the entire catchment area covering the upstream gauged area and ungauged zone, and then calibrated the SWAT model using the data in the gauged area. To verify the results, we built two hydrodynamic scenarios (the original and adjusted scenarios) for Poyang Lake using the Delft3D model. In the original scenario, the upstream boundary condition is the observed stream flow from the upstream gauged area, while, in the adjusted scenario, it is the sum of the observed stream flow from the gauged area and the simulated stream flow from the ungauged zone. The experimental results showed that there is a stronger correlation and lower bias $\left(R^{2}=0.81\right.$, PBIAS $\left.=10.00 \%\right)$ between the observed and simulated stream flow in the adjusted scenario compared to that $\left(R^{2}=0.77\right.$, PBIAS $\left.=20.10 \%\right)$ in the original scenario, suggesting the simulated stream flow of the ungauged zone is reasonable. Using this method, we estimated the stream flow of the Poyang Lake ungauged zone as $16.4 \pm 6.2$ billion $\mathrm{m}^{3} \mathrm{a}^{-1}$, representing $\sim 11.24 \%$ of the annual total water yield of the entire watershed. Of the annual water yield, $70 \%\left(11.48\right.$ billion $\left.\mathrm{m}^{3} \mathrm{a}^{-1}\right)$ is concentrated in the wet season, while $30 \%$ (4.92 billion $\left.\mathrm{m}^{3} \mathrm{a}^{-1}\right)$ comes
\end{abstract}

from the dry season. The ungauged stream flow significantly improves the water balance with the closing error decreased by 13.48 billion $\mathrm{m}^{3} \mathrm{a}^{-1}(10.10 \%$ of the total annual water resource) from $30.20 \pm 9.1$ billion $\mathrm{m}^{3} \mathrm{a}^{-1}$ (20.10\% of the total annual water resource) to $16.72 \pm 8.53$ billion $\mathrm{m}^{3} \mathrm{a}^{-1}$ ( $10.00 \%$ of the total annual water resource). The method can be extended to other lake, river, or ocean basins where observation data is unavailable.

\section{Introduction}

In recent years, floods and droughts have occurred frequently (Cai et al., 2015; Tanoue et al., 2016), threatening lives and health, reducing crop yields, and hindering economic development (Lesk et al., 2016; Smith et al., 2014). To reduce the damage to the population, agriculture, and economy, we should attempt to predict floods and droughts precisely. However, in watersheds, ungauged zones lack stream flow observations. The ungauged stream flow is difficult to estimate and is usually neglected in water yield estimations, which can result in flood/drought predictions being not accurate enough.

These ungauged zones are an area of interest in ungauged basins (Sivapalan et al., 2003). Ungauged zones, which stretch from the downstream boundary of a gauged basin to the upper boundary of an adjacent water body, exist in river, lake, and ocean catchments universally. An ungauged zone 
usually occupies a large proportion of an entire watershed (Dessie et al., 2015; Li et al., 2014); thus, neglecting ungauged zones adds uncertainty in models of estimating the water yield. In addition, the ungauged zone is usually located in flat topography with a dense river network, resulting in turbulent flow without a fixed direction. The dense river network and turbulent flow make it difficult to observe and estimate stream flow in the ungauged zone.

The stream flow simulation in ungauged zones is one area of interest in the Prediction in Ungauged Basins (PUB) research program (Hrachowitz et al., 2013; Sivapalan et al., 2003). In the PUB research program, data acquisition techniques (Hilgersom and Luxemburg, 2012), experimental studies (McMillan et al., 2012; Ali et al., 2012), advanced models and strategies (Harman, 2008), and new hydrological theories (Kleidon et al., 2013) have been developed to improve hydrological prediction results for ungauged zones.

In the PUB research program, methods for stream flow prediction in stream flow ungauged zones focus on simple water balance equations and the transformation of hydrological information (Dessie et al., 2015; Song et al., 2016). For simple water balance equations, there are no parameters to be calibrated. Feng et al. (2013) defined stream flow as the difference between precipitation and evapotranspiration. SMEC (2007) determined the stream flow of the ungauged zone based on a lake water balance equation using measured lake water levels and inflow discharges from the upstream gauged catchment. This method is not suitable for accurate stream flow simulation in the ungauged zone.

Some researchers use regionalization methods to simulate stream flow in ungauged zones. The parameters in the gauged areas are calibrated. Then, the parameters are transformed from gauged to ungauged areas. Wale et al. (2009) constructed a regional model for the relationship between the hydrological model parameters and the catchment characteristics. Based on this regional model, the hydrological parameters in the gauged area were transformed to the ungauged zone. However, verification of the ungauged stream flow is not shown in these studies.

However, other researchers have undertaken verification for the ungauged stream flow simulation. Wang et al. (2007) computed the stream flow in an ungauged zone by classifying the underlying surface. The stream flow of each type of surface was calculated based on the surface characteristics. Wang verified the estimation results by comparing the simulated and observed lake water levels. The verification in Ma and Liu (2011) was based on the water balance of yearly inflow and outflow of the lake. The time resolution is not high enough. Dessie et al. (2015) simulated stream flow in ungauged zones using a rainfall-runoff model and a runoff coefficient. Dessie et al. analyzed the effect of the ungauged zone on the water balance of the lake, which indirectly verified the stream flow simulation result of the ungauged zone. However, the water balance for indirect verification does not represent the water conservation exactly.
An approach coupling hydrology with hydrodynamics could be used to solve the simulation and verification problems. Usually, a water body (a lake, a river, or an ocean) exists downstream of the ungauged zone. The water body is gauged by stream flow gauging stations at the outlet and water level gauging stations on the water surface. The observations can be used to verify the stream flow simulation result by building a hydrodynamic model for the water body. The method coupling hydrology with hydrodynamic models is widely used to represent the catchment water system and the interaction between catchments and water bodies. Inoue et al. (2008) combined hydrology and hydrodynamic models to simulate the hydrological cycle and hydrodynamic characteristics in a coastal wetland of the Mississippi River delta with effective model performance. Dargahi and Setegn (2011) combined a watershed hydrological (soil and water assessment tool, SWAT) model with a 3-D hydrodynamic model (GEMSS) to simulate the Lake Tana basin to address the impact of climate change. Bellos and Tsakiris (2016) combined hydrological and hydrodynamic techniques for flood simulation in the Halandri catchment. However, the method combing a hydrological model and a hydrodynamic model is rarely applied in such ungauged zones. As the ungauged zone is usually located in flat topography with turbulent flow, it is difficult to draw watersheds in the ungauged zone. In addition, allocating the ungauged stream flow to the inflow boundary of a hydrodynamic model is not easy. The methods of drawing watersheds and allocating the stream flow are not mentioned in the previous studies. The details of coupling hydrology and hydrodynamic models in the ungauged are presented in the study.

The Poyang Lake Ungauged Zone (PLUZ) is a typical example of ungauged zones. The PLUZ is adjacent to Poyang Lake. There are stream flow observations at the outlet of the lake. The stream flow from the PLUZ is usually estimated as the difference between the stream flow at the outlet of the lake and the observed stream flow gauging the upstream area. However, the observations at the outlet of the lake cannot respond to the variation of the watershed hydrology quickly and accurately due to water storage and flood regulation of the lake, which makes the stream flow peak clipped and time lagged. The traditional method is too coarse for stream flow simulation in the PLUZ.

More attempts have been made at stream flow simulation in the PLUZ. Huang et al. (2011) developed a runoff flux model especially for the plain area of the PLUZ. The simulation results were verified by comparing observed stream flow at Hukou with the sum of the simulated stream flow in the PLUZ and the gauged stream flow of the gauged upstream at an annual scale. The timescale was coarse. Furthermore, the water storage and flood regulation functions of the lake were not taken into consideration. Guo et al. (2011) simulated the daily runoff of the PLUZ using the variable infiltration capacity (VIC) and multiple-input single-output system (MISO) models. The verification was performed by 

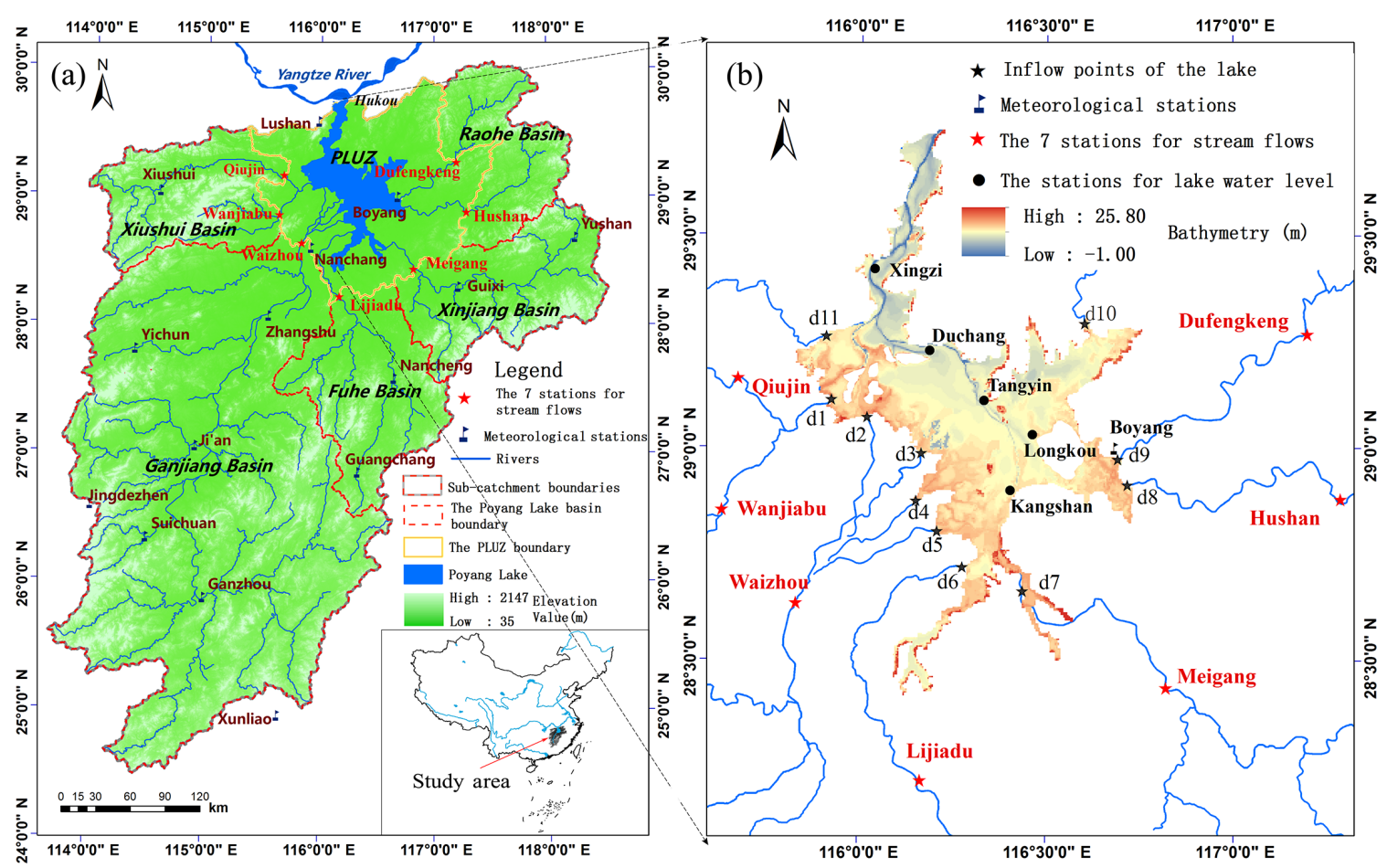

Figure 1. Study area and the related data. (a) The location of the Poyang Lake watershed, Poyang Lake Ungauged Zone (PLUZ), five major river sub-catchments, meteorological stations, and hydrological stations; (b) location of the lake, inflow points, and water level stations.

comparing the simulated results with the estimated results. However, the estimated result was derived from the time lag equation, so it could not replace the observed value exactly for the following two reasons: (1) the time lag equation was a simple hydrodynamic model for the lake, which is not very accurate; (2) in the equation, the stream flow at Hukou was adjusted by a modified coefficient at the annual scale, which is not reasonable to apply at the daily scale. Most recently, $\mathrm{Li}$ et al. (2014) combined the hydrological model (WATLAC) and hydrodynamic model (MIKE), where the stream flow in the ungauged area was calculated by the runoff coefficient. However, there was no verification. In summary, there have been few studies that include effective verification for stream flow simulations in the PLUZ. In this study, the method of combining hydrological and hydrodynamic models is introduced to solve the simulation and verification problem in the PLUZ. Our specific objectives are to (1) simulate and the verify the stream flow in the PLUZ, (2) analyze the interannual and intra-annual variations of the ungauged stream flow, and (3) analyze the impact of the ungauged stream flow on the lake water balance.

\section{Study area and data}

\subsection{Study area}

Poyang Lake is the largest freshwater lake in China and is connected with the Yangtze River in the north of Jiangxi province. The catchment is covered by the five major river sub-catchments and the ungauged zone (Fig. 1a).

As shown in Fig. 1a, the Poyang Lake basin includes three parts: the gauged area (the five major river catchments), ungauged zone (the PLUZ) and Poyang Lake. The stream flow of the gauged area was measured by seven stream flow stations (Qiujin, Wanjiabu, Waizhou, Lijiadu, Meigang, Hushan, and Dufengkeng). The PLUZ is a plain area and stretches from the seven stream flow stations to the boundary of Poyang Lake. The PLUZ covers an area of $19867 \mathrm{~km}^{2}$, and amounts to $12 \%$ of the lake catchment. The discharges from the gauged area and the PLUZ flow into the lake. Then the water discharges into the Yangtze River at Hukou. The Poyang Lake basin, with an area of $162000 \mathrm{~km}^{2}$, has a subtropical wet climate characterized by a mean annual precipitation of $1680 \mathrm{~mm}$ and annual average temperature of $17.5^{\circ} \mathrm{C}$. The topography of the Poyang Lake basin varies from upstream hills at an elevation of approximately $2100 \mathrm{~m}$ to downstream plain areas at an elevation of almost $35 \mathrm{~m}$ above sea level. The topography of the PLUZ is flat, with a slope of less than $5^{\circ}$. 
The elevation of the lake bed generally decreases from the south to the north, with differences of approximately $7 \mathrm{~m}$, as shown in Fig. 1b. The discharges from the gauged area and the ungauged zone flow into the lake at 11 points $\left(d_{1} \ldots d_{11}\right)$. The water level is controlled by the representative stations of Kangshan, Duchang, and Xingzi.

\subsection{Data}

We provide data for SWAT and Delft3D models. Data required by the SWAT model include the forcing elements of daily rainfall, evapotranspiration, temperature, relative humidity, and wind from 1980 to 2014 collected at 16 national meteorological stations. The stations are distributed uniformly across the area (Fig. 1a). These data were downloaded from the China Meteorological Data Sharing Service System (http://data.cma.cn/). The digital elevation model (DEM) of the catchment originates from SRTM (Shuttle Radar Topography Mission) in 2000. The spatial resolution of the DEM is $90 \mathrm{~m}$. The land-use data were obtained from Landsat TM and ETM+ images in 2000 (Chen et al., 2007). Land use was categorized into forest $(54 \%)$, farmland $(25 \%)$, pasture $(10 \%)$, water bodies $(5 \%)$, bare land $(3 \%)$, urbanization $(2 \%)$, and wetland $(1 \%)$. The soil data were generated from the Harmonized World Soil Database (FAO, 1995). The soil has the following catchment-aggregated proportions: Haplic Acrisols (55\%), Cumulic Anthrosols (22\%), Humic Acrisols (11\%), Haplic Alisols (3\%), Haplic Luvisols (2\%), and others (7\%). The long time series daily discharges at seven gauging stations (Qiujin, Wanjiabu, Waizhou, Lijiadu, Meigang, Dufengkeng, Hushan) from 2000 to 2011 were obtained from the Jiangxi Hydrological Information Network (http://www.jxsw.cn/). Data required by Delft3D Model included the lake shoreline, topographic data (Qi et al., 2016; Zhang et al., 2015), and hydrological observations. The shoreline was delineated based on the remote sensing image of Poyang Lake during the flood period in 1998, which is the maximum surface area of the lake. The topographic data were measured by the Changjiang Water Resources Commission of China (http://www.cjw.gov.cn). The daily water level at the stations of Xingzi, Duchang, and Kangshan and discharges at Hukou from 2000 to 2011 were downloaded from the Jiangxi Hydrological Information Network.

\section{Methodology}

The procedure for the ungauged stream flow simulation and verification contains three parts (Fig. 2): (1) hydrologic modeling for the Poyang Lake ungauged zone; (2) hydrodynamic modeling for Poyang Lake in two scenarios with or without considering the ungauged stream flow; (3) coupling of hydrological and hydrodynamic models.
In the first procedure, we built a SWAT model for the entire catchment covering the gauged area and the ungauged zone to simulated stream flow in the PLUZ, and calibrated and validated the SWAT model using the gauged stream flow in the gauged area. In the second procedure, we built the original and adjusted scenarios for the lake hydrodynamic model to further verify the ungauged stream flow. The original scenario did not take the ungauged stream flow into consideration, unlike the adjusted scenario, which accounted for the ungauged zones. In the adjusted scenario, the hydrological and hydrodynamic modes were coupled. In the third procedure, we described the coupling of river hydrological and lake hydrodynamic models in details.

In order to analyze the impact of ungauged stream flow on the lake water balance, we described the water balance equation in Sect. 3.4.

\subsection{Hydrology modeling}

We used a SWAT model (Arnold et al., 1993) to simulate stream flow in the PLUZ. SWAT is a physically based, semidistributed, and river-basin-scale hydrological model. It has been developed to assess the impact of land management practices on stream flow, sediment and agricultural yields in complex basins with changing soil types, and land use and management over long periods of time. For the purpose of modeling, an entire watershed is divided into sub-watersheds based on rivers and DEM data. Sub-watersheds are portioned into hydrological response units (HRUs), the minimum research units. Water balance is the driving force of hydrological processes. The hydrological cycle includes two divisions: runoff producing on land and flow routing in channels. The surface runoff volume is calculated using the Soil Conservation Service method (USDA Soil Conservation Service, 1972). Flow routed through the channel is calculated by the variable storage coefficient method (Williams, 1969. SWAT has already been widely applied to watersheds around the world for stream flow simulation (Douglas-Mankin et al., 2010; Arnold et al., 2012; Luo et al., 2016).

A SWAT model should be calibrated and validated by the measured data. The PLUZ is ungauged for stream flow, while there are stream flow gauging stations (the seven gauging stations) at the upstream boundary of the PLUZ, controlling the upstream gauged area (Fig. 1a). Thus, we established a SWAT model for a larger area, more than just the ungauged zone. The modeled area covers the upstream gauged area and the ungauged zone (the PLUZ), excluding Poyang Lake (Fig. 1a). We use the long time series of monthly discharges at six gauging stations (Wanjiabu, Waizhou, Lijiadu, Meigang, Dufengkeng and Hushan) to perform the calibration from 2000 to 2005 and validation from 2006 to 2011. The determination coefficient $\left(R^{2}\right)$, Nash-Sutcliffe efficiency coefficient (NSE), percent bias (PBIAS), and root mean square error (RMSE) are used as the performance indices. 


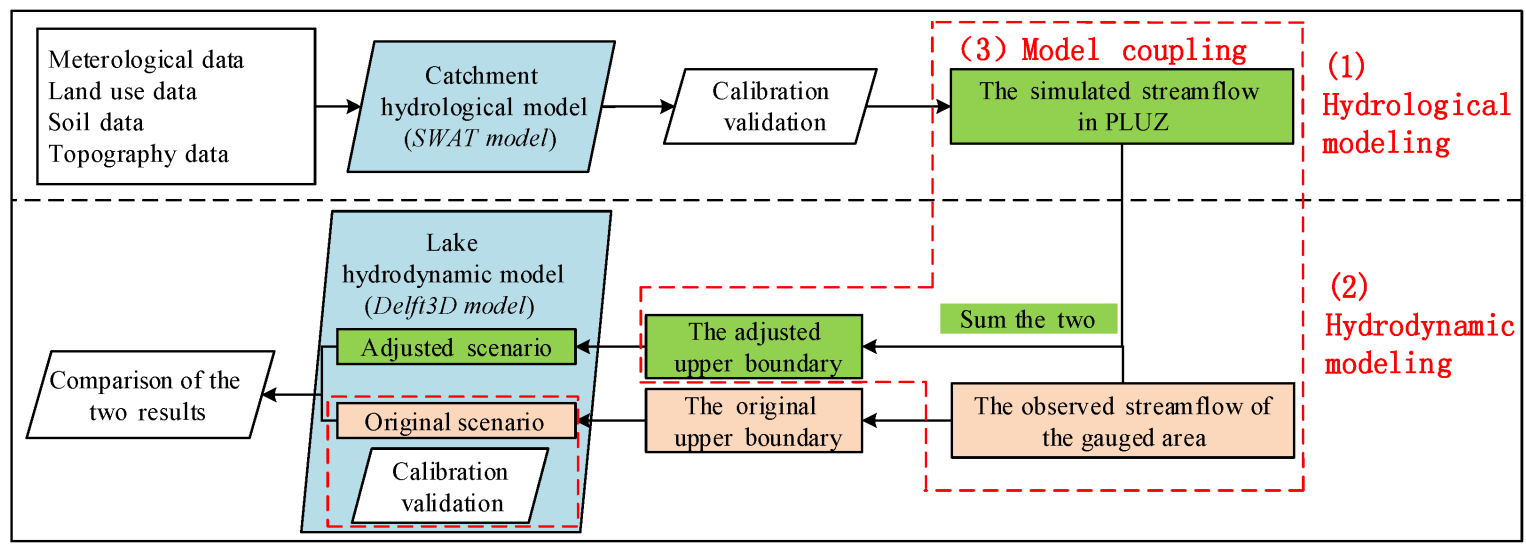

Figure 2. Conceptual flow chart for stream flow simulation and verification in ungauged zones by coupling hydrological and hydrodynamic models. The flow chart includes three parts: hydrological modeling, hydrodynamic modeling, and model coupling.

\subsection{Hydrodynamic modeling}

To verify the stream flow simulation results in the PLUZ, we built two hydrodynamic scenarios for the lake using the Delft3D model. Delft3D simulates the hydrodynamic pattern via the Delft3D-FLOW (Roelvink and van Banning, 1994) module. Delft3D-FLOW is a multi-dimensional (twoor three-dimension) hydrodynamic and transport simulation program. The program can calculate unsteady flow by building linear or curvilinear grids suitable for the water boundary, which is forced by tidal and meteorological data. Delft3DFLOW is based on the Reynolds-averaged Navier-Stokes (RANS) equations, which are simplified for an incompressible fluid under shallow water and Boussinesq assumptions. The RANS equations are solved by the alternative direction implicit finite difference method (ADI) on a spherical or orthogonal curvilinear grid. Delft3D has ability to simulate water level variations and flows on surface water bodies in response to forcing elements of inflow discharges and climate factors, which has been proven by applications on many surface water bodies around the world. Delft3D is considered appropriate for the wide and shallow characteristics of Poyang Lake.

In the model, the shoreline of lake was delineated as the maximum area of the lake surface to ensure that the dynamic changes in the lake's surface area did not surpass the inundation area. To better capture the rapid dynamic of inundation area and minimize the computational effort, the size of the model grids ranged from 200 to $300 \mathrm{~m}$. The topographic data were interpolated into each computational node of the model grids. The water level was initialized as the mean of the three hydrological stations in Poyang Lake on 1 January 2001, which are Xingzi, Duchang, and Kangshan. The corresponding velocities were initialized as zero. The upper open boundary was set as the upstream discharges. The lower open boundary was specified as the observed long time series of the daily water level at Hukou station. The model was run from 1 January 2001 to 31 December 2010 and the time step was set as 5 min to meet the Courant-Friedrich-Levy criteria for a stable condition. The long time series of observed data for water levels at Xingzi, Duchang, and Kangshan gauging stations, and outflow discharges at Hukou gauging station, were used for calibration from 2001 to 2005 and validation from 2006 to 2010.

Two scenarios were established, the adjusted scenario and the original scenario. We applied the same hydrodynamic model (Delft3D) in the same study area (Poyang Lake) as the research by Zhang et al. (2015). Therefore, we set the parameters (the Manning roughness coefficient, the eddy viscosity parameter, and the critical water depth for wetting and drying) as the fittest ones calibrated by Zhang et al. (2015) for the Delft3D model. The parameters in the two scenarios are set the same.

The original scenario did not take stream flow in the PLUZ into consideration, unlike the adjusted scenario, which accounted for the ungauged zones. In the original scenario, the upper open boundary was the stream flow from the gauged area, set as the daily discharges from the seven gauging stations; there are nine inflow points $-\mathrm{d} 1, \mathrm{~d} 2, \mathrm{~d} 3, \mathrm{~d} 4, \mathrm{~d} 5, \mathrm{~d} 6$, d7, d8, and d (Fig. 1b) for the lake model. In the adjusted scenario, the upper boundary was the stream flow from the gauged and ungauged areas, set as the sum of the measured discharges at the seven gauging stations and the simulated stream flow in the PLUZ; there are 11 inflow points $-\mathrm{d} 1, \mathrm{~d} 2$, d3, d4, d5, d6, d7, d8, d9, d10, and d11 (Fig. 1b) for the lake model. The specific upstream conditions for the two scenarios are listed in Table 1.

\subsection{Model coupling}

As the ungauged zone is usually in low and flat topography with turbulent flow, it is difficult to draw watersheds in the ungauged zone. Additionally, allocating the stream flow 
Table 1. The upstream boundary conditions of the Delft3D model in the original and adjusted scenarios. Od1, Od2, Od3, Od4, Od5, Od6, Od7, Od8, and Od9 represent the stream flow set at d1, d2, d3, d4, d5, d6, d7, d8, and d9, respectively, in the original scenario. Ad1, Ad2, Ad3, Ad4, Ad5, Ad6, Ad7, Ad8, Ad9, Ad10, and Ad11 represent the stream flow set at d1, d2, d3, d4, d5, d6, d7, d8, d9, d10, and d11, respectively, in the adjusted scenario. b1, b2 ..., and b13 represent the sub-basins in the PLUZ (Fig. 3b). $Q_{\mathrm{gau}, d_{\mathrm{i}}}$ and $Q_{\mathrm{ungau}, d_{\mathrm{i}}}$ represent the gauged and ungauged stream flow gathering to the point of $d_{i}$, respectively. $Q_{\text {ungau, } d_{\mathrm{i}}}$ will be calculated in the model linking section (seen Table 2).

\begin{tabular}{|c|c|c|}
\hline Scenarios & Inflow points & Stream flow set at different points \\
\hline \multirow[t]{9}{*}{ Original scenario } & d1 & Od1: the observed stream flow at the Qiujin station $\left(Q_{\mathrm{gau}, \mathrm{d} 1}\right)$ \\
\hline & $\mathrm{d} 2$ & Od2: $50 \%$ of the observed stream flow at the Wanjiabu station $\left(Q_{\mathrm{gau}, \mathrm{d} 2}\right)$ \\
\hline & $\mathrm{d} 3$ & Od3: $10 \%$ of the observed stream flow at the Wanjiabu station $\left(Q_{\mathrm{gau}, \mathrm{d} 3}\right)$ \\
\hline & $\mathrm{d} 4$ & Od4: $20 \%$ of the observed stream flow at the Wanjiabu station $\left(Q_{\mathrm{gau}, \mathrm{d} 4}\right)$ \\
\hline & $\mathrm{d} 5$ & Od5: $20 \%$ of the observed stream flow at the Wanjiabu station $\left(Q_{\mathrm{gau}, \mathrm{d} 5}\right)$ \\
\hline & d6 & Od6: the observed stream flow at the Lijiadu station $\left(Q_{\text {gau,d6 }}\right)$ \\
\hline & $\mathrm{d} 7$ & Od7: the observed stream flow at the Meigang station $\left(Q_{\mathrm{gau}, \mathrm{d} 7}\right)$ \\
\hline & $\mathrm{d} 8$ & Od8: the observed stream flow at the Hushan station $\left(Q_{\mathrm{gau}, \mathrm{d} 8}\right)$ \\
\hline & d9 & Od9: the observed stream flow at the Dufengkeng station $\left(Q_{\mathrm{gau}, \mathrm{d} 9}\right)$ \\
\hline \multirow[t]{11}{*}{ Adjusted scenario } & $\mathrm{d} 1$ & Ad1: the summation of $Q_{\text {ungau,d1 }}$ and $Q_{\mathrm{gau}, \mathrm{d} 1}$ \\
\hline & $\mathrm{d} 2$ & Ad2: the summation of $Q_{\text {ungau,d2 }}$ and $Q_{\text {gau,d2 }}$ \\
\hline & $\mathrm{d} 3$ & Ad3: the summation of $Q_{\text {ungau,d3 }}$ and $Q_{\text {gau,d3 }}$ \\
\hline & $\mathrm{d} 4$ & Ad4: the summation of $Q_{\text {ungau,d4 }}$ and $Q_{\mathrm{gau}, \mathrm{d} 4}$ \\
\hline & $\mathrm{d} 5$ & Ad5: the summation of $Q_{\text {ungau,d5 }}$ and $Q_{\text {gau,d5 }}$ \\
\hline & d6 & Ad6: the summation of $Q_{\text {ungau,d6 }}$ and $Q_{\mathrm{gau}, \mathrm{d} 6}$ \\
\hline & $\mathrm{d} 7$ & Ad7: the summation of $Q_{\text {ungau,d7 }}$ and $Q_{\mathrm{gau}, \mathrm{d} 7}$ \\
\hline & $\mathrm{d} 8$ & Ad8: the summation of $Q_{\text {ungau,d8 }}$ and $Q_{\mathrm{gau}, \mathrm{d} 8}$ \\
\hline & d9 & Ad9: the summation of $Q_{\text {ungau,d } 9}$ and $Q_{\mathrm{gau}, \mathrm{d} 9}$ \\
\hline & $\mathrm{d} 10$ & Ad10: $Q_{\text {ungau,d10 }}$ \\
\hline & $\mathrm{d} 11$ & Ad11: $Q_{\text {ungau,d11 }}$ \\
\hline
\end{tabular}

in the ungauged zone to inflow boundary of hydrodynamic model is not an easy task.

\subsubsection{Drawing the watersheds for the ungauged zone}

The upper boundary condition of the hydrodynamic model in the adjusted scenario is the sum of the gauged stream flow from the gauged area and the simulated stream flow from the ungauged zone (the PLUZ). To determine the upper boundary condition in the adjusted scenario, we coupled the hydrological model and hydrodynamic model in space and time.

To make sure the hydrological model and hydrodynamic model were coupled perfectly in space, the delineated subbasins, rivers, and the outlets of the PLUZ basin should follow the following constraints. (1) River networks in the PLUZ must be delineated to link the five major rivers and the inflow points of the lake. (2) The seven gauging stations must be set as the outlets of the gauged basins and the inlets of the PLUZ basin, and the most downstream boundary of the gauged basins should coincide with the most upstream boundary of the PLUZ basin. (3) The outlets of the PLUZ must completely coincide with the inflow points of the lake in the hydrodynamic model, and the most downstream boundary of the PLUZ basin should coincide with the boundary of the lake. (4) The sub-basins of the PLUZ should cover the whole area of the PLUZ. Following these principles, the catchment hydrological model can be seamlessly coupled with the lake hydrodynamic model in space. We first drew the sub-basins, rivers, and outlets using the SWAT model. Since the delineated results from the SWAT model may not satisfy these constraints, we edited the rivers, the boundary of sub-basins, and the outlets to meet the constraints (Fig. 2).

As shown in Fig. 2, the PLUZ was divided to 14 sub-basins (b1, b2 $\left.\ldots b_{\mathrm{i}} \ldots \mathrm{b} 14\right)$, and the gauged area was divided into 25 sub-basins (b15, b16 ... $\left.b_{\mathrm{i}} \ldots \mathrm{b} 39\right)$. Consequently, 11 outlets of the whole catchment were produced for adjusted scenario, coinciding with the lake inflow points $-\mathrm{d} 1, \mathrm{~d} 2, \mathrm{~d} 3, \mathrm{~d} 4, \mathrm{~d} 5$, d6, d7, d8, d9, d10, d11.

The calibration and validation of the SWAT model was conducted at a monthly scale. However, hydrodynamic model simulation is at a daily scale. To couple the two models in the same timescale, we use the same parameters of the monthly SWAT model to simulate the ungauged stream flow at the daily scale.

\subsubsection{Allocating stream flow}

To allocate the ungauged stream flow to different inflow points of the lake, the sub-basins were sorted into 11 groups

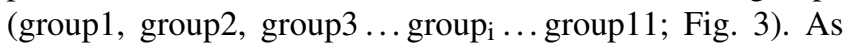
shown in Fig. 3, the sub-basins in the same group (group $\left.{ }_{i}\right)$ drains to the same inflow point $\left(d_{i}\right)$. 


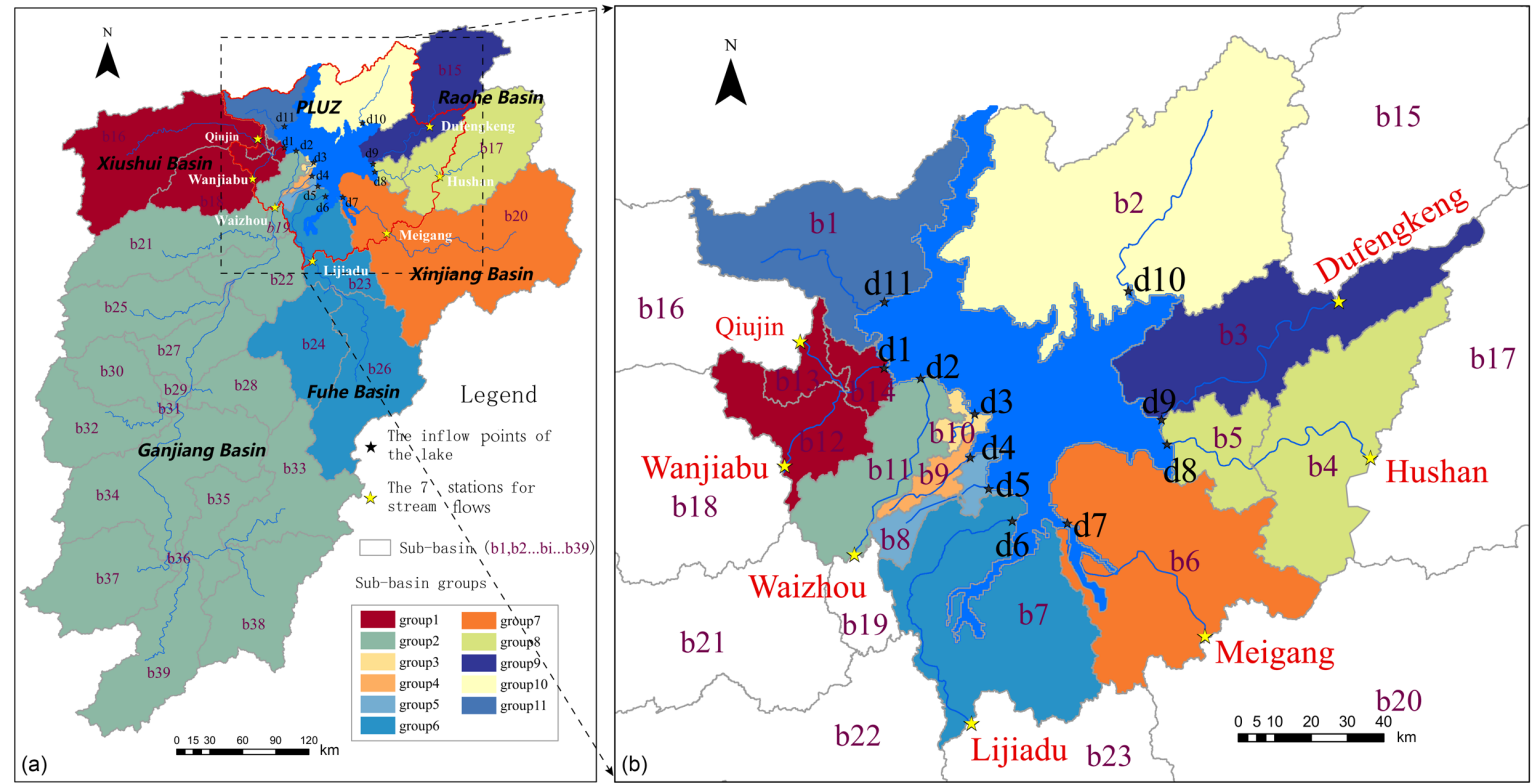

Figure 3. The abridged general view coupling the catchment and lake models in space: (a) stream flow partition scheme from the whole basin to the inflow points $\left(\mathrm{d} 1, \mathrm{~d} 2 \ldots d_{\mathrm{i}} \ldots \mathrm{d} 9\right)$ of the lake; (b) stream flow partition scheme from the PLUZ to the inflow points $\left(\mathrm{d} 1, \mathrm{~d} 2 \ldots d_{\mathrm{i}} \ldots \mathrm{d} 11\right)$ of the lake. The sub-basins in the same group (group $\mathrm{i}_{\mathrm{i}}$ colored the same) drains to the same inflow point $\left(d_{\mathrm{i}}\right)$ of the lake. In particular, in the model, 50, 30, 10, and $10 \%$ of the stream flow from sub-basins in Ganjiang sub-catchment was set to flow into the lake at points d2, d3, d4, and $\mathrm{d} 5$, respectively.

Based on the sub-basin groups, we determined the ungauged stream flow gathering to each inflow point of the lake. The stream flow produced by the PLUZ gathering to $d_{\mathrm{i}}$, is calculated as the difference between the SWAT simulated outflows at the outlets of the whole catchment and the gauged area. The ungauged stream flow contributing to each lake inflow point is listed in Table 2.

Over time, water yield can reflect the total amount. So we analyzed the water yield variable instead of stream flow. Water yield is computed as the accumulative stream flow in a specific duration. Monthly water yield is the accumulative stream flow in a specified month. Annual water yield is the accumulative stream flow in a specified year. In the paper, the units of stream flow, monthly water yield, and annual water yield are $\mathrm{m}^{3} \mathrm{~s}^{-1}, \mathrm{~m}^{3}$ month ${ }^{-1}$, and $\mathrm{m}^{3} \mathrm{a}^{-1}$, respectively.

\subsection{Analysis of lake water balance}

In order to analyze the effect of ungauged zone on the lake balance, we construct water balance equations for the lake based on water conservation principles that the difference between input and output stream flow equals storage change of the lake, as follows:

$Q_{\text {in }}+P-E+G+\Delta S+\varepsilon^{\prime}=Q_{\text {out }}$,

where $Q_{\text {in }}$ denotes the inflow from the river basins, $P$ is the precipitation in the lake, $\Delta S$ is the storage change of the lake, and $Q_{\text {out }}$ represents the observed outflow at Hukou of the lake. $\varepsilon^{\prime}$ represents the uncertainties in the water balance, which arise from errors in observed data and other components, such as the ungauged stream flow and model uncertainty. $E$ represents the evapotranspiration of the lake, less than $2 \%$ of the lake outflow. The $E$ data are obtained from Nanchang climatology station. $G$ represents the ground water exchange, only $1.3 \%$ of the total water balance ( $\mathrm{Li}$ et al., 2014). Thus, we combine $E, G$, and $\varepsilon^{\prime}$ as the closing error $\varepsilon$. As the summation of $Q_{\mathrm{in}}, P$, and $\Delta S$ can be simulated by the hydrodynamic model, the summation is set as the simulated stream flow at Hukou. Traditionally (in the original scenario), $Q_{\text {in }}$ omits the ungauged stream flow. The water balance equation can be described as follows:

$Q_{\text {SimOut }, \text { org }}+\varepsilon_{\text {org }}=Q_{\text {out }}$,

where $Q_{\text {SimOut,org }}$ represents the simulated stream flow at Hukou from the hydrodynamic model in the original scenario, and $\varepsilon_{\text {org }}$ represents the uncertainty of the equation, which arise from ignoring the ungauged stream flow, $E, G$, the error in the observed data, and the uncertainty of the hydrodynamic model. As the ungauged zone occupies $12 \%$ of the total water balance components ( $\mathrm{Li}$ et al., 2014), much larger than the other components ( $E$ and $G$, less than $3.3 \%$ ), the closing error should be larger than zero on the assumption that the observed data and hydrodynamic model are of sufficient accuracy.

When the ungauged stream flow is taken account (in the adjusted scenario), $O_{\text {in }}$ contains the gauged and the un- 
Table 2. The ungauged stream flow allocated to the lake inflow points of the dynamic model in the adjusted scenario. $Q_{\mathrm{ungau}, d_{\mathrm{i}}}$ represents the ungauged stream flow gathering to the inflow points of $d_{i} . \mathrm{d} 1, \mathrm{~d} 2, \mathrm{~d} 3 \ldots \mathrm{d} 11$ are the inflow points in the Delft3D model and the outlets in the SWAT model (Figs. $1 \mathrm{~b}$ and 3). b1, b2, b3 ... b11 are the sub-basins in the PLUZ (Fig. 3b). $Q_{\text {swat, } d_{\mathrm{i}}}$ represent the simulated discharges at the outlet (di) from the SWAT model. $Q_{\text {swat, Qiujin }}, Q_{\text {swat,Wanjiabu }}, Q_{\text {swat, Waizhou }}, Q_{\text {swat,Lijiadu }}, Q_{\text {swat,Meigang }}, Q_{\text {swat,Hushan }}$, and $Q_{\text {swat,Dufengkeng }}$ represent the simulated discharges at the outlets of Qiujin, Waizhou, Lijiadu, Meigang, Hushan, and Dufengkeng, respectively, from the SWAT model.

\begin{tabular}{|c|c|c|}
\hline Lake inflow point $\left(d_{\mathrm{i}}\right)$ & Sub-basins draining to $d_{\mathrm{i}}$ & Ungauged stream flow gathering to $d_{i}$ \\
\hline $\mathrm{d} 1$ & b12, b13 and b14 & $Q_{\text {ungau,d1 }}: Q_{\text {swat,d1 }}-Q_{\text {swat,Qiujin }}-Q_{\text {swat,Wanjiabu }}$ \\
\hline $\mathrm{d} 2$ & b11 & $Q_{\text {ungau }, \mathrm{d} 2}: Q_{\text {swat }, \mathrm{d} 2}-50 \% \times Q_{\text {swat, Waizhou }}$ \\
\hline $\mathrm{d} 3$ & b10 & $Q_{\text {ungau,d3 }}: Q_{\text {swat,d3 }}-10 \% \times Q_{\text {swat, Waizhou }}$ \\
\hline $\mathrm{d} 4$ & b9 & $Q_{\text {ungau,d4 }}: Q_{\text {swat,d4 }}-20 \% \times Q_{\text {swat, Waizhou }}$ \\
\hline d5 & b8 & $Q_{\text {ungau,d5 }}: Q_{\text {swat, } \mathrm{d} 5}-20 \% \times Q_{\text {swat, Waizhou }}$ \\
\hline d6 & b7 & $Q_{\text {ungau,d6: }}: Q_{\text {swat,d6 }}-Q_{\text {swat,Lijiadu }}$ \\
\hline $\mathrm{d} 7$ & b6 & $Q_{\text {ungau,d7 }}: Q_{\text {swat,d7 }}-Q_{\text {swat,Meigang }}$ \\
\hline $\mathrm{d} 8$ & b4 and b5 & $Q_{\text {ungau,d } 8}: Q_{\text {swat }, \mathrm{d} 8}-Q_{\text {swat,Hushan }}$ \\
\hline d9 & b3 & $Q_{\text {ungau, } \mathrm{d} 9}: Q_{\text {swat }, \mathrm{d} 9}-Q_{\text {swat,Dufengkeng }}$ \\
\hline $\mathrm{d} 10$ & b2 & $Q_{\text {ungau }, \mathrm{d} 10}: Q_{\text {swat }, \mathrm{d} 10}$ \\
\hline d11 & b1 & $Q_{\text {ungau,d11 }}: Q_{\text {swat }, \mathrm{d} 11}$ \\
\hline Total & b1, b2, b3, b4, b5, b6, b7, b8, b9, b10, b11 & 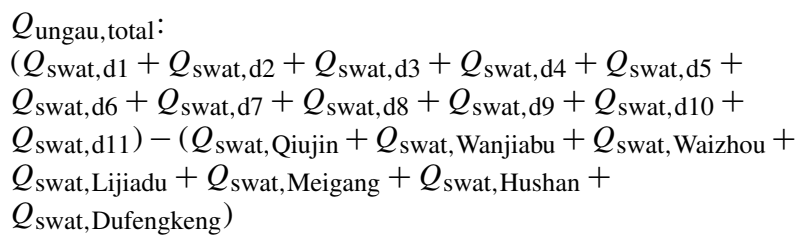 \\
\hline
\end{tabular}

gauged stream flow. The water balance equation can be described as follows:

$Q_{\text {SimOut,adj }}+\varepsilon_{\text {adj }}=Q_{\text {out }}$,

where $Q_{\text {SimOut,adj }}$ represents the simulated stream flow at Hukou from the hydrodynamic model in the adjusted scenario, and $\varepsilon_{\text {adj }}$ represents the uncertainty of the equation, which arise from ignoring $E, G$, the error in the observed data, and uncertainty of the hydrodynamic model and the simulated ungauged stream flow result. The partial uncertainties (caused by ignoring $E, G$, the error in the observed data, and uncertainty of the hydrodynamic model) in the adjusted scenario and original scenario are the same. Thus, if the simulated ungauged stream by the SWAT model are of sufficient accuracy, the uncertainty in the adjusted scenario $\left(\varepsilon_{\text {adj }}\right)$ should be smaller than that in the original scenario $\left(\varepsilon_{\text {org }}\right)$.

\section{Results and discussion}

\subsection{Calibration and validation of SWAT model and Delft3D model}

To adjust the models to be applied in the Poyang Lake basin, we undertook calibration and validation for the SWAT model and the Delft3D model. Table 3 and Fig. 4 show the calibration and validation results for the SWAT model. The obser- vations and simulations at the six gauging stations (Wanjiabu, Waizhou, Lijiadu, Meigang, Hushan, and Dufengkeng) come to satisfactory agreement, with an $R^{2}$ or NSE larger than 0.70 and an absolute PBIAS less than $20 \%$, except for Wanjiabu Station. The agreement is also supported by the high consistency between the observations and the simulation in terms of amplitude and phase, although the simulated peak stream flow did not accurately match the observations, producing underestimation and overestimation (Fig. 4). Nevertheless, the calibration and validation results demonstrate that the SWAT model is generally capable of simulating the stream flow of the catchment.

Table 4 and Fig. 5 show the calibration and validation results for the Delft3D model. The observations and simulations at the four gauging stations (Xingzi, Duchang, Kangshan, and Hukou) come to satisfactory agreement, with an $R^{2}$ or NSE larger than 0.70 and an absolute PBIAS less than $25 \%$. The agreement is also supported by the high consistency between the observation and simulation, although there are obvious discrepancies during the low water level period (Fig. 5a, b, c) and the highly changed flow velocity period (Fig. 5d). The mismatch probably arises from the decreased elevation of lake bed from the south to the north and the dynamic variation between wetlands and lake areas. The dynamic variation causes the lake to be a river in dry periods and turn into a lake in flood periods, which is difficult to accurately model. Nonetheless, model calibration and validation results demonstrate that the Delft3D model has the capa- 
Table 3. Quantitative assessment of calibration and validation for SWAT model.

\begin{tabular}{llrrr|rrr}
\hline \multirow{2}{*}{ Gauging Station } & Index & \multicolumn{2}{c}{ Model calibration (2000-2005) } & \multicolumn{2}{c}{ Model validation (2006-2011) } \\
\cline { 3 - 7 } & & $R^{2}$ & NSE & PBIAS (\%) & $R^{2}$ & NSE & PBIAS (\%) \\
\hline Wanjiabu & monthly discharge & 0.63 & 0.61 & -0.2 & 0.78 & 0.76 & 9.4 \\
Waizhou & monthly discharge & 0.94 & 0.93 & 3.2 & 0.95 & 0.93 & 6.5 \\
Lijiadu & monthly discharge & 0.84 & 0.82 & -9.4 & 0.88 & 0.85 & -16.8 \\
Meigang & monthly discharge & 0.89 & 0.89 & 1.1 & 0.91 & 0.90 & 10.0 \\
Hushan & monthly discharge & 0.81 & 0.78 & 14.2 & 0.76 & 0.75 & 13.9 \\
Dufengkeng & monthly discharge & 0.80 & 0.80 & -4.7 & 0.83 & 0.80 & 9.4 \\
\hline
\end{tabular}

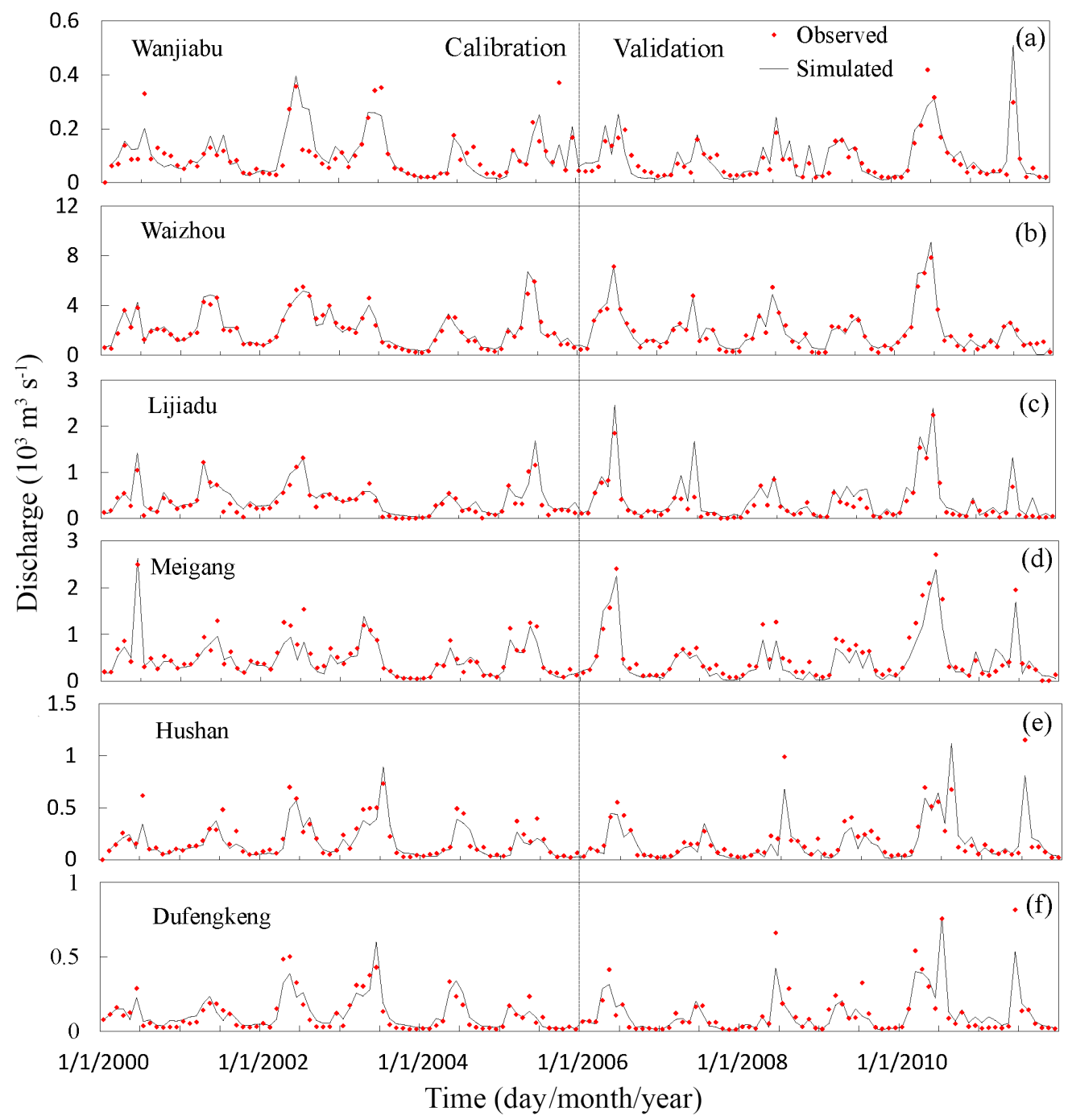

Figure 4. Comparison of observations and the results simulated from the SWAT model for calibration (2000-2005) and validation (20062011). Panels (a), (b), (c), (d), (e), and (f) are the calibration and validation results for stations at Wanjiabu, Waizhou, Lijiadu, Meigang, Hushan, and Dufengkeng, respectively. 


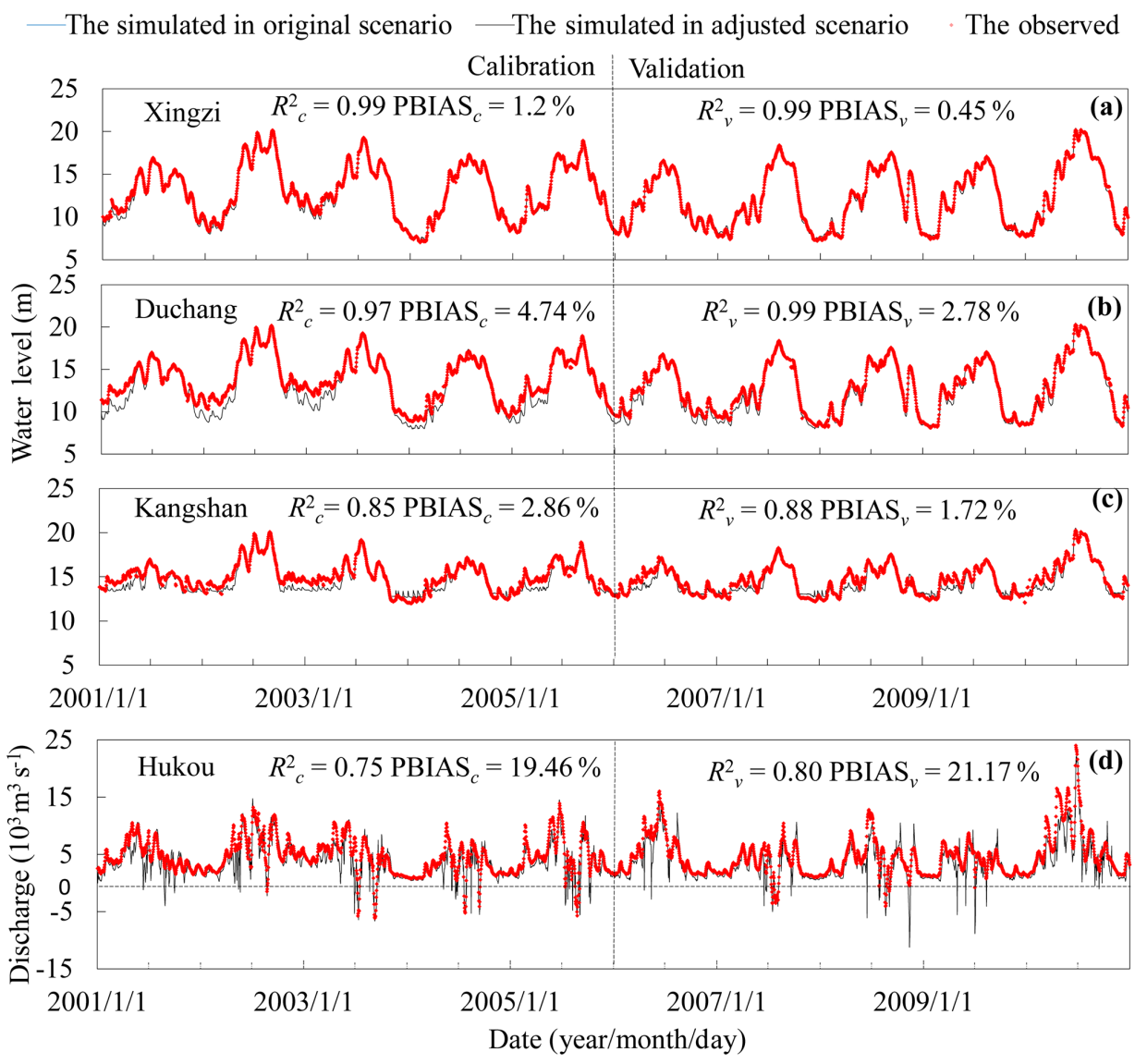

Figure 5. Comparison of the observed (red dotted line) and simulated (black solid line) lake water level at Xingzi, Duchang, and Kangshan stations and outflow discharges at Hukou by the Delft3D model. The calibration period and validation period are from 2001 to 2005 and from 2006 to 2010 , respectively. $R_{\mathrm{c}}^{2}, \mathrm{PBIAS}_{\mathrm{c}}$ and $R_{\mathrm{v}}^{2}, \mathrm{PBIAS}_{\mathrm{v}}$ are the calibration (from 2001 to 2005) and validation (from 2001 to 2005 ) results, respectively.

Table 4. Quantitative assessment of calibration and validation for stream flow simulation for the Delft3D model.

\begin{tabular}{|c|c|c|c|c|c|c|c|c|c|}
\hline \multirow[t]{3}{*}{ Gauging station } & \multirow[t]{3}{*}{ Index } & \multicolumn{6}{|c|}{ Original scenario } & \multirow{2}{*}{\multicolumn{2}{|c|}{$\begin{array}{c}\text { Adjusted scenario } \\
\text { All (2001-2010) }\end{array}$}} \\
\hline & & \multicolumn{2}{|c|}{ Calibration (2001-2005) } & \multicolumn{2}{|c|}{ Validation (2006-2010) } & \multicolumn{2}{|c|}{ All (2001-2010) } & & \\
\hline & & $R^{2}$ & PBIAS (\%) & $R^{2}$ & PBIAS (\%) & $R^{2}$ & PBIAS (\%) & $R^{2}$ & PBIAS (\%) \\
\hline Xingzi & lake water level & 0.99 & 1.2 & 0.99 & 0.45 & 0.99 & 0.85 & 0.99 & 0.48 \\
\hline Duchang & lake water level & 0.97 & 4.74 & 0.99 & 2.78 & 0.97 & 3.18 & 0.97 & 2.67 \\
\hline Kangshan & lake water level & 0.85 & 2.86 & 0.88 & 1.72 & 0.86 & 1.56 & 0.86 & 1.21 \\
\hline Hukou & lake outflow discharge & 0.75 & 19.46 & 0.80 & 21.47 & 0.77 & 20.10 & 0.81 & 10.00 \\
\hline
\end{tabular}

bility to simulate the hydrodynamic characteristics of Poyang Lake.

\subsection{Stream flow verification in the ungauged zone}

To further verify the stream flow simulation results in the ungauged zone, we compared the two hydrodynamic simulation results from the adjusted scenario and original scenario. The adjusted scenario took the stream flow in the PLUZ into consideration, while the original scenario omitted the stream flow in the PLUZ. The hydrodynamic simulation result in the adjusted scenario is improved compared to the original scenario, shown in Table 4 and Fig. 6.

Table 4 shows the results of the two scenarios in two aspects: the lake water level and outflow. For the lake water level, the absolute PBIAS decreases from 0.85, 3.18, and $1.56 \%$ in the original scenario to $0.48,2.67$, and $1.21 \%$ in the adjusted scenario while $R^{2}$ stays the same. The simulated water level result is only slightly improved when inflow to the lake increase by $\sim 10 \%$, due to the large area of the 

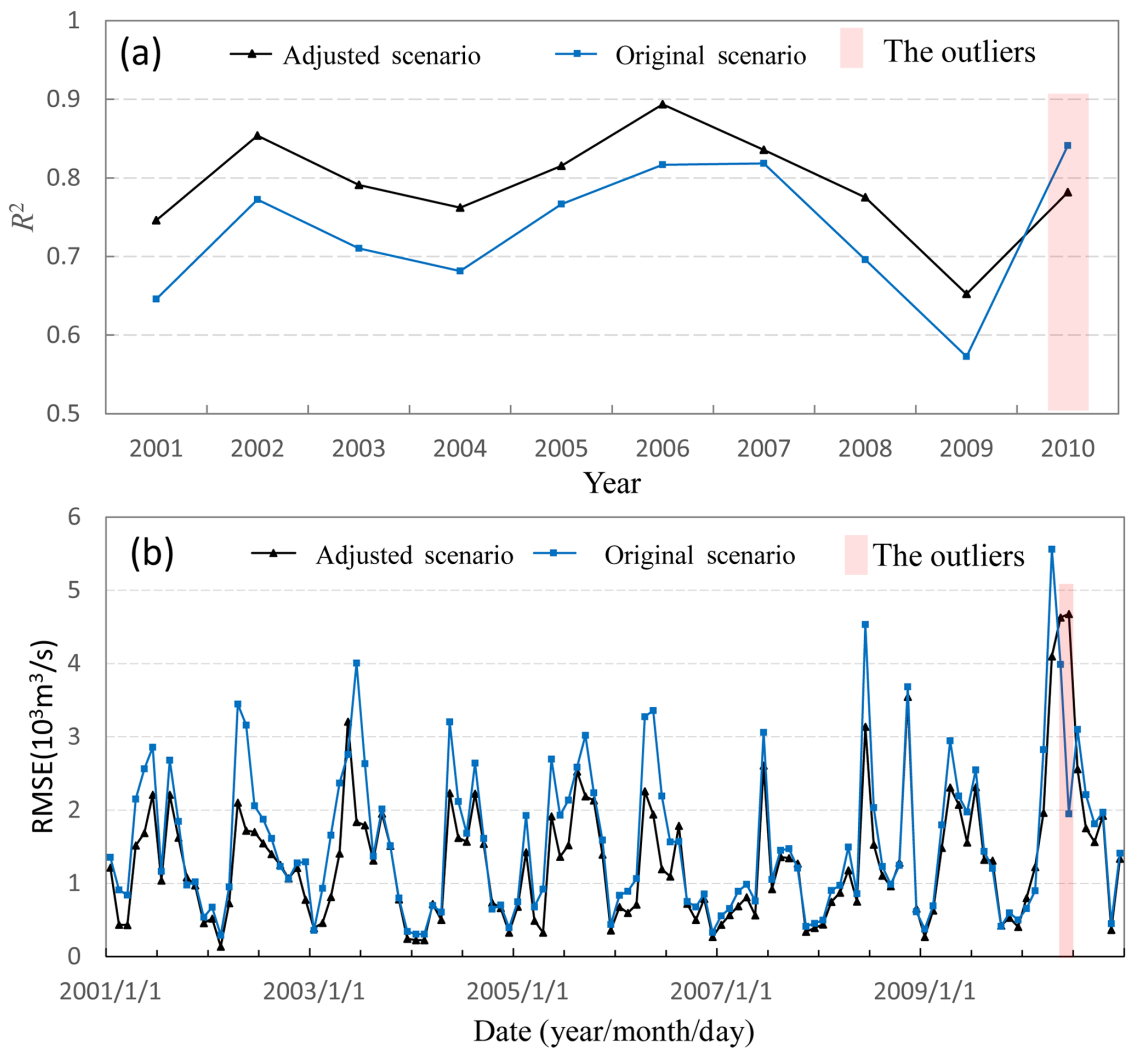

Figure 6. Comparison of the simulated stream flow results at Hukou, in the adjusted scenario and original scenario. The outlier is the data which may be affected by the dike burst in 2010 .

lake. In fact, the simulated water level is already good enough $\left(R^{2}>0.85\right.$, the absolute of PBIAS $\left.<4 \%\right)$ in the original scenario. It is not easy to improve the simulated water level result by adding the inflow, only $\sim 10 \%$ of the total water resource. However, for the lake outflow discharges, the simulated results in the adjusted scenario produce a higher $R^{2}(0.81)$ and lower absolute PBIAS $(10.00 \%)$, compared to that $\left(R^{2}=0.77\right.$ and PBIAS $\left.=20.01 \%\right)$ in the original scenario. The evidence suggests an improved simulation result in the adjusted scenario when the ungauged stream flow is taken into account, compared to that in the original scenario when the ungauged stream flow is neglected. The result indicates the simulated ungauged result is reasonable.

Figure 6 show the comparison of the stream flow simulated accuracy in the adjusted scenario and original scenario. The $R^{2}$ value is larger and RMSE is smaller in the adjusted scenario than that in the original scenario during the period from 2001 to 2009. The larger $R^{2}$ and smaller RMSE indicates a more significant correlation and narrower discrepancy between the simulated and observed stream flow in the adjusted scenario. The improved simulated result of the hydrodynamic model in the adjusted scenario indicates that the ungauged simulated stream flow is reasonable. Although in 2010 the simulated result in the adjusted scenario is not better than that in the original scenario (red shading in the Fig. 6), the opposite result may be caused by the dike burst in the Fuhe Basin (Feng et al., 2011) since the SWAT model and Delft3D model do not consider the dike burst. Thus, it does not demonstrate the ungauged stream flow is unreasonable in 2010 .

\subsection{Stream flow simulation result of the ungauged zone}

We do monthly (Fig. 7) and annual (Fig. 8) statistical analysis of the ungauged stream flow, to study the intra-annual and interannual variations. As shown in Fig. 7, monthly water yield of the ungauged zone shows clearly seasonality. In a particular year, the maximum monthly water yield varies from 1.676 to 7.712 billion $\mathrm{m}^{3}$ month $^{-1}$, occurring between April and July (Fig. 7a and b); and the minimum monthly water yield varies from 0 to 0.508 billion $\mathrm{m}^{3}$ month $^{-1}$, occurring between November and the next February (Fig. 7a and b). In the Poyang Lake basin, precipitation is mainly concentrated in the period from March to July (the wet season) and there is less rain during the period from September to next March (the dry season; Fig. 7c). Nearly $70 \%$ of the annual stream flow and nearly $65 \%$ of the annual precipitation come from the wet season. The ungauged stream flow seasonal variations are consistent with the change of the precip- 


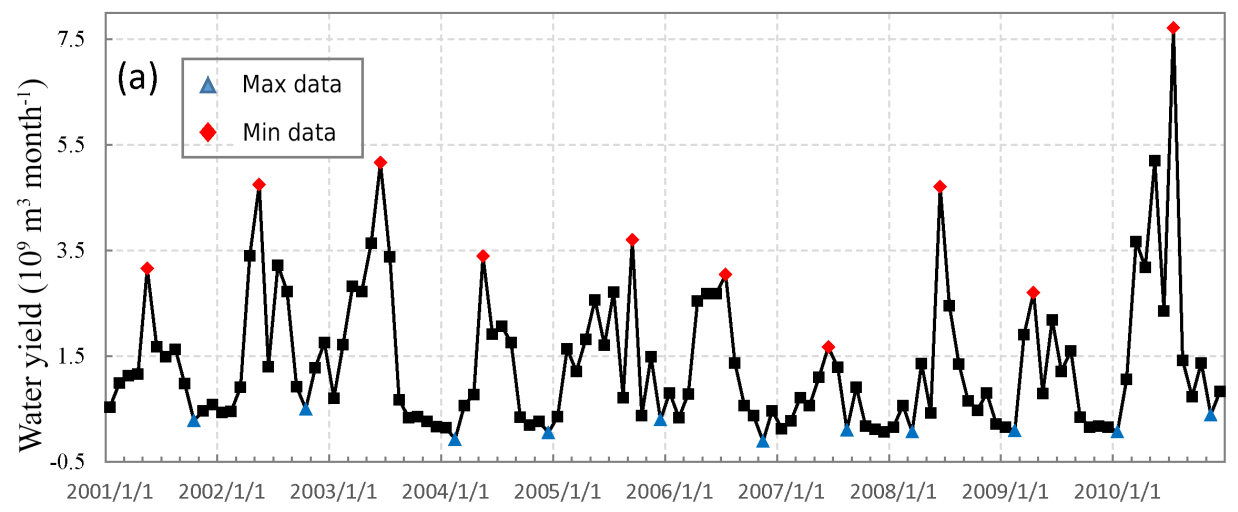

Date (year/month/day)
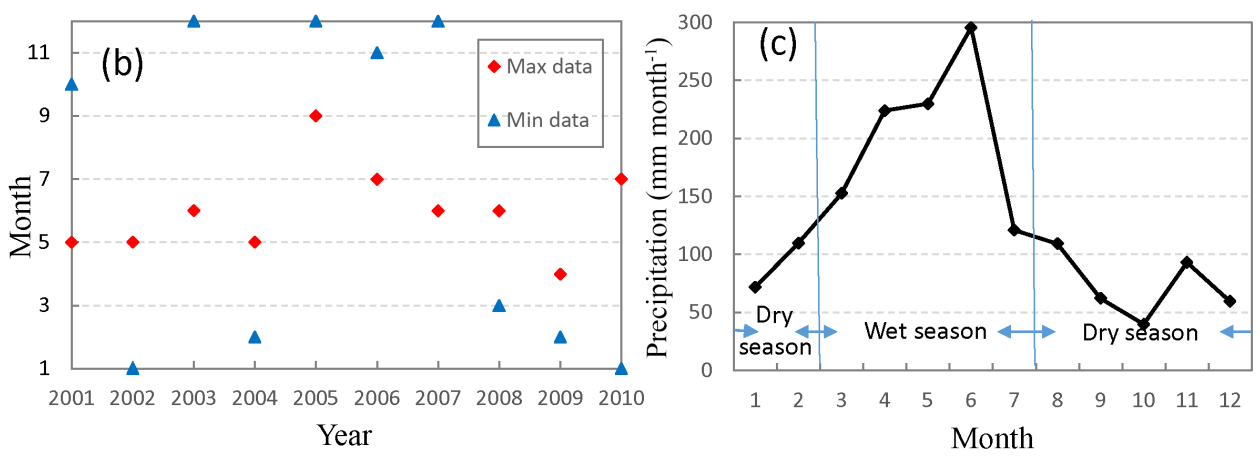

Figure 7. (a) The monthly mean water yield for each month from January 2001 to December 2010 produced by the PLUZ. (b) Maximum and minimum water yield month distributed from 2001 to 2010. (c) The mean monthly precipitation from 2001 to 2010 at Nanchang meteorological station derived from China's meteorological networks. Max data and min data represent the monthly maximum water yield and monthly minimum water yield in the particular year, respectively.

itation, as precipitation is one of the important driving forces for stream flow.

Interannual variation is also apparent. Both the month and amount of maximum monthly water yield appear different in different years, as well as that of minimum monthly water yield. For 10 years (2001-2010), the maximum monthly water yield occurred in 2010, when 5 of 12 months had high stream flow (Fig. 7a). Indeed, a flooding event happened in June 2010 due to the dike burst, which risked the lives of more than 10000 people. The minimum monthly water yield reached the minimum in 2007. In fact, in 2007 Jiangxi province experience severe drought (Feng et al., 2011). The severe flood and drought can also be suggested in Fig. 8. As the water yield is affected by the extreme climate, the long time series of water yields can also reflect flood/drought conditions in Poyang Lake area, in reverse.

Annual stream flow of the ungauged zone shows a clear declining trend $(P<0.05$, from $t$ test), at a rate of -1.02 billion $\mathrm{m}^{3} \mathrm{a}^{-1}$ (dashed line in Fig. 8) during the period from 2001 to 2009. The annual stream flow in the dry and wet season decreased by -0.67 billion $\mathrm{m}^{3} \mathrm{a}^{-1}$ and -0.34 billion $\mathrm{m}^{3} \mathrm{a}^{-1}$, respectively, from 2001 to 2009 . In
2010, the annual stream flow recovered to a high level of 28.07 billion $\mathrm{m}^{3} \mathrm{a}^{-1}$.

The mean annual water yield in the PLUZ totals $16.4 \pm 6.2$ billion $\mathrm{m}^{3}$, encompassing $11.24 \%$ of that from the whole Poyang Lake watershed. The result is close to that from Li et al. (2014), where the ungauged stream flow amounts to $\sim 12 \%$. The similar results indicate that the stream flow simulation result of the PLUZ is reasonable. Of the annual water yield, nearly $70 \%\left(11.48\right.$ billion $\left.\mathrm{m}^{3}\right)$ is concentrated in the wet season, while $30 \%\left(4.92\right.$ billion $\mathrm{m}^{3}$ ) comes from the dry season. Such a large contribution to the inflow of Poyang Lake could have a large effect on the water balance of the lake.

\subsection{The impact of the ungauged zone on the water balance}

In order to analyze the impact of the ungauged stream flow on the lake water balance (seen in Sect. 3.4), we calculate the closing errors based on Eqs. (2) and (3): $\varepsilon_{\text {adj }}$ when the ungauged stream flow is considered (the adjusted scenario) and $\varepsilon_{\text {org }}$ when the ungauged stream flow is omitted (the original scenario; Fig. 9). As shown in Fig. 9, for most months 


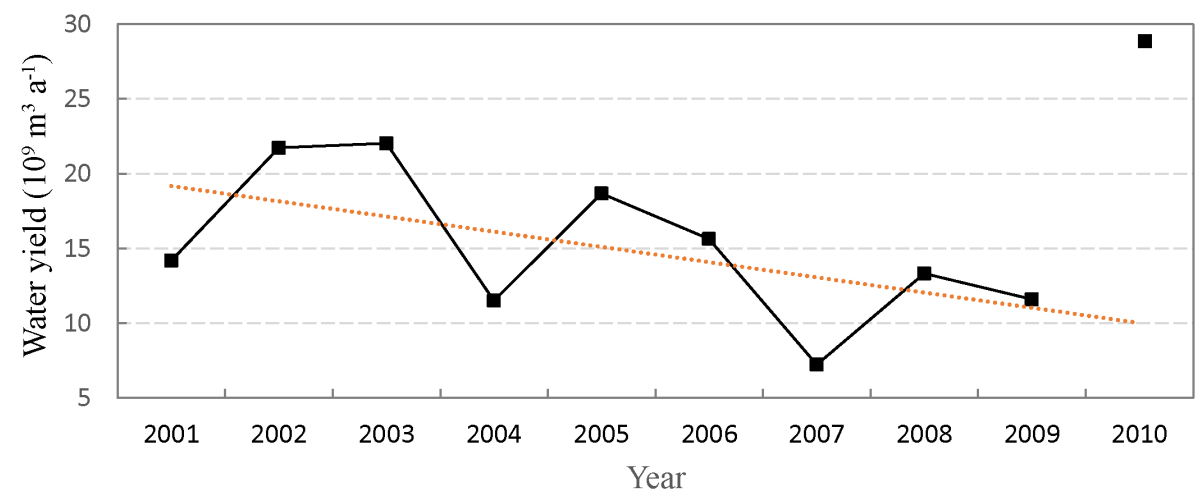

Figure 8. The variation trend of the annual water yield of the ungauged zone from 2001 to 2009 . It shows declining trend at a rate -1.02 billion $\mathrm{m}^{3} \mathrm{a}^{-1}(P<0.05)$.

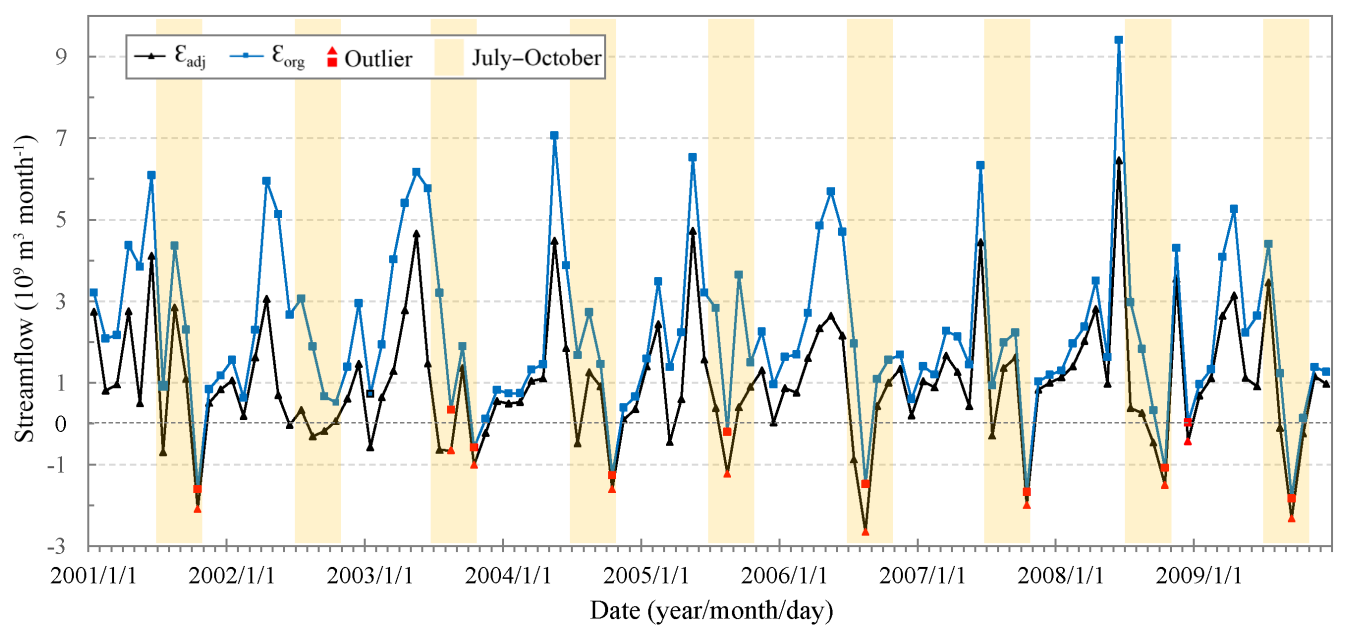

Figure 9. Closing errors of lake water balance: $\varepsilon_{\text {org }}$ and $\varepsilon_{\text {adj }} \cdot \varepsilon_{\text {org }}$ is the closing error when the ungauged stream flow is considered and $\varepsilon_{\text {adj }}$ is the closing error when the ungauged stream flow is omitted. Outliers are the point pairs, of which $\varepsilon_{\text {org }}$ is smaller than $\varepsilon_{\text {adj }}$. The outliers are different from the other point pairs, of which the $\varepsilon_{\text {org }}$ is larger than $\varepsilon_{\text {adj }}$.

(nearly $83 \%$ ), the absolute value of $\varepsilon_{\text {adj }}$ is smaller than that of $\varepsilon_{\mathrm{org}}$, which demonstrates that ungauged stream flow improves the lake water balance.

However, there are some exceptional dot pairs colored in red (outlier, only $17 \%$ ) in Fig. 9. For the exceptional, the absolute $\varepsilon_{\text {adj }}$ is not less than the absolute $\varepsilon_{\text {org }}$ as the above. All the exceptional is almost concentrated in the high flow period from July to October (Fig. 9). That is an unstable stage when backward flow from Yangtze River usually appears, and the water level of Yangtze River usually keeps high (David et al., 2006); this can result in dynamically changed flow. Thus, more uncertainties are added to the measured data and the hydrodynamic model during unstable season (July to October) compared to the stable season (months from November to the next January). Dynamically changed flow may cause the stream flow to be overestimated randomly. High water level of Yangtze River also can lead to overestimated stream flow at Hukou, compared to the conditions in normal wa- ter level. Additionally, frequent water abstraction for irrigation from July to October can also strength the overestimation situation. The accumulative estimation can even lead to a closing error of less than zero from July to October (Fig. 9), contrary to the closing error greater than zero as described in Sect. 3.4. The evidence suggests that the hydrodynamic model is not accurate enough to simulate the stream flow during the unstable season. During this time, the added input component could make the overestimated stream flow even greater. Thus, the closing error will be extended. This is why when $\varepsilon_{\text {org }}$ is less than zero, $\varepsilon_{\text {adj }}$ will be even more negative (the red dot pairs in Fig. 9). The evidence demonstrates that the hydrodynamic model is not accurate enough to simulate the lake input components during the unstable season from July to October. It does not deny the role of ungauged simulated stream flow in improving the lake water balance.

The ungauged stream flow decreases the annual average closing error of water balance by 13.48 billion $\mathrm{m}^{3} \mathrm{a}^{-1}$ 
$(10.10 \%$ of the total annual water resource), from $30.20 \pm 9.1$ billion $\mathrm{m}^{3} \mathrm{a}^{-1}(20.10 \%$ of the total annual water resource) to $16.72 \pm 8.53$ billion $\mathrm{m}^{3} \mathrm{a}^{-1}(10.00 \%$ of the total annual water resource) for 2001-2010. The evidence also suggests the ungauged simulated stream flow is reasonable.

\section{Conclusions}

A method coupling hydrology and hydrodynamics can be used to simulate and verify stream flow in ungauged zones, solving the simulation and verification problems caused by the unavailability of stream flow observations.

The hydrological and hydrodynamic models are coupled seamlessly in both space and time. The method of coupling the models was presented in detail for the first time and was applied in the case study successfully. Using this method, we estimated that the ungauged zone of Poyang Lake produces a stream flow of approximately 16.4 billion $\mathrm{m}^{3}$, representing approximately $11.4 \%$ of the total inflow from the entire watershed. The ungauged stream flow significantly improves the water balance with the closing error decreased by 13.48 billion $\mathrm{m}^{3} \mathrm{a}^{-1}(10.10 \%$ if the total annual water resource), from 30.20 billion $\mathrm{m}^{3} \mathrm{a}^{-1}$ (20.10\% of the total annual water resource) to 16.72 billion $\mathrm{m}^{3} \mathrm{a}^{-1}$ (10.00\% of the total annual water resource).

The method can be extended to other lake, river, or ocean basins where stream flow observation data are unavailable, producing reasonable stream flow simulation results in ungauged zones. Reliable stream flow simulation results in ungauged zones contribute to more accurate and reliable water yield predictions, which provides a deep understanding of hydrology for hydrological engineers and scientists and helps governments develop better water management plans. Furthermore, this method is an area of interest of the Prediction in Ungauged Basins (PUB) research program and provides stream flow prediction and validation aids in PUB research.

Data availability. All data can be accessed as described in Sect. 2.2.

Competing interests. The authors declare that they have no conflict of interest.

Special issue statement. This article is part of the special issue "Coupled terrestrial-aquatic approaches to watershed-scale water resource sustainability". It is not associated with a conference.

Acknowledgements. This work was funded by the National Natural Science Funding of China (NSFC, 41331174), the National Key Research and Development Program (2017YFB0504103), the Open Foundation of Jiangxi Engineering Research Center of
Water Engineering Safety and Resources Efficient Utilization (OF201601), and the LIESMARS special research funding.

Edited by: Xuesong Zhang

Reviewed by: two anonymous referees

\section{References}

Ali, G., Tetzlaff, D., Soulsby, C., McDonnell, J. J., and Capell, R.: A comparison of similarity indices for catchment classification using a cross-regional dataset, Adv. Water Resour., 40, 11-22, https://doi.org/10.1016/j.advwatres.2012.01.008, 2012.

Arnold, J. G., Allen, P. M., and Bernhardt, G.: A comprehensive surface-groundwater flow model, J. Hydrol., 142, 47-69, https://doi.org/10.1016/0022-1694(93)90004-S, 1993.

Arnold, J. G., Moriasi, D. N., Gassman, P. W., Abbaspour, K. C., White, M. J., Srinivasan, R., Santhi, C., Harmel, R. D., Griensven, A. V., VanLiew, M. W., Kannan, N., and Jha, M. K.: Swat: Model Use, Calibration, and Validation, T. ASABE, 55, 1491-1508, https://doi.org/10.13031/2013.34915, 2012.

Bellos, V. and Tsakiris, G.: A hybrid method for flood simulation in small catchments combining hydrodynamic and hydrological techniques, J. Hydrol., 540, 331-339, 2016.

Cai, W., Wang, G., Santoso, A., McPhaden, M. J., Wu, L., Jin, F.-F., Timmermann, A., Collins, M., Vecchi, G., Lengaigne, M., England, M. H., Dommenget, D., Takahashi, K., and Guilyardi, E.: Increased frequency of extreme La Niña events under greenhouse warming, Nature Climate Change, 5, 132-137, https://doi.org/10.1038/nclimate2492, 2015.

Dargahi, B. and Setegn, S. G.: Combined 3D hydrodynamic and watershed modelling of Lake Tana, Ethiopia, J. Hydrol., 398, 4464, https://doi.org/10.1016/j.jhydrol.2010.12.009, 2011.

David, S. and Qiaoli, L.: Landscape changes and increasing flood frequency in China's Lake Poyang Region, Prof. Geogr., 55, 434-445, https://doi.org/10.1111/0033-0124.5504003. 2003.

Dessie, M., Verhoest, N. E. C., Pauwels, V. R. N., Adgo, E., Deckers, J., Poesen, J., and Nyssen, J.: Water balance of a lake with floodplain buffering: Lake Tana, Blue Nile Basin, Ethiopia, J. Hydrol., 522, 174-186, https://doi.org/10.1016/j.jhydrol.2014.12.049, 2015.

Douglas-Mankin, K. R., Srinivasan, R., and Arnold, J. G.: Soil and Water Assessment Tool (SWAT) model: Current developments and applications, T. ASABE, 53, 1423-1431, https://doi.org/10.13031/2013.34915, 2010.

Feng, L., Hu, C., Chen, X., and Li, R.: Satellite observations make it possible to estimate Poyang Lake's water budget[J], Environ. Res. Lett., 6, 044023, https://doi.org/10.1088/17489326/6/4/044023, 2011.

Feng, L., Hu, C., Chen, X., and Zhao, X.: Dramatic inundation changes of China's two largest freshwater lakes linked to the Three Gorges Dam, Environ. Sci. Technol., 47, 9628-9634, https://doi.org/10.1021/es4009618, 2013.

Guo, J., Guo, S., and Li, T.: Daily runoff simulation in Poyang Lake intervening basin based on remote sensing data, Procedia Environmental Sciences, 10, 2740-2747, https://doi.org/10.1016/j.proenv.2011.09.425, 2011.

Harman, C.: A similarity framework to assess controls on shallow subsurface flow dynamics in hillslopes, Water Resource Re- 
search, 45, 206-218, https://doi.org/10.1029/2008WR007067, 2009.

Hilgersom, K. P. and Luxemburg, W. M. J.: Technical Note: How image processing facilitates the rising bubble technique for discharge measurement, Hydrol. Earth Syst. Sci., 16, 345-356, https://doi.org/10.5194/hess-16-345-2012, 2012.

Hrachowitz, M., Savenije, H. H. G., Blöschl, G., McDonnell, J. J., Sivapalan, M., Pomeroy, J. W., Arheimer, B., Blume, T., Clark, M. P., Ehret, U., Fenicia, F., Freer, J. E., Gelfan, A., Gupta, H. V., Hughes, D. a., Hut, R. W., Montanari, A., Pande, S., Tetzlaff, D., Troch, P. A., Uhlenbrook, S., Wagener, T., Winsemius, H. C., Woods, R. A., Zehe, E., and Cudennec, C.: A decade of Predictions in Ungauged Basins (PUB) - a review, Hydrologica Sciences Journal, 58, 1198-1255, https://doi.org/10.1080/02626667.2013.803183, 2013.

Huang, S. Y., Wang, L. C., Chen, X. L., and Huo, Y.: A semidistributed hydrological model and its application based on a plain river-net area, Resources \& Environment in the Yangtze Basin, 20, 44-50, 2011.

Inoue, M., Park, D., Justic, D., and Wiseman, W. J.: A highresolution integrated hydrology-hydrodynamic model of the Barataria Basin system, Environ. Model. Softw., 23, 1122-1132, https://doi.org/10.1016/j.envsoft.2008.02.011, 2008.

Kleidon, A., Zehe, E., Ehret, U., and Scherer, U.: Thermodynamics, maximum power, and the dynamics of preferential river flow structures at the continental scale, Hydrol. Earth Syst. Sci., 17, 225-251, https://doi.org/10.5194/hess-17-225-2013, 2013.

Lesk, C., Rowhani, P., and Ramankutty, N.: Influence of extreme weather disasters on global crop production, Nature, 529, 84-87, https://doi.org/10.1038/nature16467, 2016.

Li, Y., Zhang, Q., Yao, J., Werner, A. D., and Li, X.: Hydrodynamic and Hydrological Modeling of the Poyang Lake Catchment System in China, J. Hydrol. Eng., 19, 607-616, https://doi.org/10.1061/(ASCE)HE.1943-5584.0000835, 2014.

Luo, K., Tao, F., Moiwo, J. P., and Xiao, D.: Attribution of hydrological change in Heihe River Basin to climate and land use change in the past three decades, Scientific reports, 6, 33704, https://doi.org/10.1038/srep33704, 2016.

Ma, X. and Liu, D.: Modeling of interval runoff in the region of Dongting Lake[J], Journal of Hydroelectric Engineering, 30, 10 15, 2011.

McMillan, H., Tetzlaff, D., Clark, M., and Soulsby, C.: Do timevariable tracers aid the evaluation of hydrological model structure? A multimodel approach, Water Resour. Res., 48, 5501, https://doi.org/10.1029/2011WR011688, 2012.
Qi, H., Lu, J., Chen, X., Sauvage, S., and Sanchez-Pérez, J. M.: Water age prediction and its potential impacts on water quality using a hydrodynamic model for Poyang Lake, China, Environ. Sci. Pollut. Res., 23, 13327-13341, https://doi.org/10.1007/s11356016-6516-5, 2016.

Roelvink, J. A. and van Banning, G. K. F. M.: Design and development of DELFT3D and application to coastal morphodynamics, Oceanographic Literature Review, 11, 451-456, 1995.

Sivapalan, M., Takeuchi, K., Franks, S. W., Gupta, V. K., Karambiri, H., Lakshmi, V., Liang, X., McDonnell, J. J., Mendiondo, E. M., O'Conell, P. E., Oki, T., Pomeroy, J. W., Schertzer, D., Uhlenbrook, S., and Zehe, E.: IAHS Decade on Predictions in Ungauged Basins (PUB), 2003-2012: Shaping an exciting future for the hydrological sciences, Hydrolog. Sci., 48, 857-880, https://doi.org/10.1623/hysj.48.6.857.51421, 2003.

SMEC: Hydrological Study of the Tana-Beles Sub-Basins, Surface water Iinvestigation, Technical Report. Ministry of Water Resources, Addis Ababa, Ethiopia, 2007.

Smith, L. T., Aragao, L. E., Sabel, C. E., and Nakaya, T.: Drought impacts on children's respiratory health in the Brazilian Amazon, Scientific reports, 4, 3726, https://doi.org/10.1038/srep03726, 2014.

Song, J., Xia, J., Zhang, L., Wang, Z. H., Wan, H., and She, D.: Streamflow prediction in ungauged basins by regressive regionalization: a case study in Huai River Basin, China, Hydrol. Res. 47, 1053-1068, https://doi.org/10.2166/nh.2015.155, 2016.

Tanoue, M., Hirabayashi, Y., and Ikeuchi, H.: Global-scale river flood vulnerability in the last 50 years, Scientific reports, 6, 36021, https://doi.org/10.1038/srep36021, 2016.

USDA Soil Conservation Service: National Engineering Handbook Section 4 Hydrology, chap. 4-10, U.S. Dept. of Agriculture, Soil Conservation Service, Washington, D.C., 1972.

Wale, A., Rientjes, T. H. M., Gieske, A. S. M., and Getachew, H. A.: Ungauged catchment contributions to Lake Tana's water balance, Hydrol. Process., 23, 3682-3693, https://doi.org/10.1002/hyp.7284, 2009.

Wang, C. H., Wang, J., Cheng, W. H., and Zhu, Y.: Numerical simulation of runoff yield and confluence in plain area, Journal of Hohai University, 35, 627-632, 2007.

Williams, J. R.: Flood Routing With Variable Travel Time or Variable Storage Coefficients[J], T. ASAE, 12, 100-103, 1969.

Zhang, P., Lu, J., Feng, L., Chen, X., Zhang, L., Xiao, X., and Liu, H.: Hydrodynamic and inundation modeling of China's largest freshwater lake aided by remote sensing data, Remote Sens., 7, 4858-4879, https://doi.org/10.3390/rs70404858, 2015. 